\title{
Periodistas españoles caídos en 'combate': 'víctimas' de distintas coberturas
}

\author{
Coral MORERA HERNÁNDEZ \\ Universidad de Valladolid \\ cmorera@hmca.uva.es
}

Recibido: 16 de junio de 2013

Aceptado: 20 de enero de 2014

\begin{abstract}
Resumen
El presente estudio analiza la cobertura dedicada por La Vanguardia, $A B C$ y El País, a la muerte de nueve periodistas españoles en diferentes conflictos bélicos. Mediante un análisis comparativo, describimos las estrategias y protocolos informativos seguidos por estos diarios en aras de conocer qué factores han influido en la mayor o menor atención dedicada, así como en la construcción y narración de los hechos. La prensa debería utilizar los mismos parámetros para abordar hechos de similares características; el tratamiento dedicado a estas muertes se convierte en un ejemplo útil para ilustrar la coherencia o complicidad de la prensa cuando acomete una temática con la que guarda mayor implicación.
\end{abstract}

Palabras clave: Prensa, corresponsal, Agenda Setting, conflictos bélicos, framing

\section{Spanish journalists killed in 'action': ‘victims' of different coverages}

\begin{abstract}
This study analyzes the coverage offered by La Vanguardia, ABC and El País, to the death of nine Spanish journalists in different belic conflicts. Through a comparative analysis, we describe the strategies and protocols followed by these newspapers in order to find out which factors have influenced the degree of attention dedicated, as well as in the making and narration of these events. The press should use the same parameters to describe events of similar characteristics. The treatment dedicated to these deaths becomes a useful example to illustrate the consistency or complicity of the press when approaches a topic which with it has greater involvement.
\end{abstract}

Keywords: Press, war reporter, Agenda Setting, belic conflicts, framing

\section{Referencia normalizada}

MORERA HERNÁNDEZ, Coral (2014): "Periodistas españoles caídos en 'combate': 'víctimas' de distintas coberturas”. Estudios sobre el Mensaje Periodístico. Vol. 20, Núm. 1 (enero-junio), págs.: 505-522. Madrid, Servicio de Publicaciones de la Universidad Complutense.

Sumario: 1. Introducción. 2. Luis Espinal. 3. Juantxu Rodríguez. 4. Jordi Pujol Puente. 5. Luis Valtueña. 6. Miguel Gil Moreno. 7. Julio Fuentes. 8. Julio A. Parrado. 9. José Couso. 10. Ricardo Ortega. 11. Resultados. 12. Conclusiones. 13. Referencias bibliográficas.

\section{Introducción}

Desde 1980 hasta el año 2004, nueve periodistas españoles han perdido la vida tiroteados, asesinados a sangre fría, víctimas de fuegos cruzados entre bandos, de misiles e incluso de tanques, en conflictos que han tenido lugar en diferentes puntos geográficos. Con motivo del reportaje emitido por TVE coincidiendo con el veinte aniversario de la muerte de Juantxu Rodríguez, fotógrafo de El País, la Presidenta de Reporteros Sin Fronteras, María Dolores Masana, señalaba que aunque hubieran 
muerto periodistas en otras épocas, ahora habían pasado de ser "un blanco ocasional, a un objetivo buscado por las mirillas de las partes enfrentadas".

Los códigos éticos y deontológicos, así como los teóricos en la materia, expresan tácitamente que los medios deben mantener unos parámetros uniformes y coherentes a la hora de abordar hechos de la misma gravedad y de similares características, (Suárez, 2001: 28). El caso que nos ocupa favorece un interesante análisis sobre cómo ha actuado la prensa en un tema que le afecta de forma tan directa. Nos interesa, por tanto, conocer el tratamiento mediático que ha recibido cada una de esas muertes en conflictos distintos y distantes, y desde una perspectiva cronológica amplia que permita obtener conclusiones de interés. No hay análisis académicos que se hayan ocupado de la producción mediática en los casos de corresponsales de guerra fallecidos en las fechas en las que nos hemos centrado ${ }^{2}$. Tampoco hay estudios sobre ninguno de nuestros actores ${ }^{3}$.

El marco teórico toma como punto de partida los postulados de la Agenda Setting, (McCombs, y Shaw, 1972), atendiendo a la cobertura que siguen los medios de dedicar más importancia a unos hechos en detrimento de otros. Nos interesa localizar el nivel de influencia del "efecto Agenda" en el objeto de estudio, qué factores han influido en la construcción de las noticias y en la importancia dedicada a las mismas. Asimismo perseguimos identificar de qué forma la prensa aborda la muerte de un corresponsal y a qué otros factores puede estar sujeta la mayor o menor atención dedicada. Por último, nos interesa establecer comparaciones entre la propia cobertura de cada fallecido, y entre la posición de los periódicos seleccionados.

Perseguimos un análisis de contenido de base cuantitativa y cualitativa y para ello elegimos tres cabeceras de entidad, La Vanguardia, $A B C$ y El Pais, que cubren todo el período de análisis. Seleccionamos y analizamos las piezas informativas que tuvieron como epicentro la muerte de los periodistas, y no aquellas que hacen referencia a ella en algún momento determinado o con relación a temas - premios, homenajes, etc- que no se circunscriben con la causa de su fallecimiento en el ejercicio de su profesión.

En la siguiente tabla exponemos los datos de los periodistas sobre cuya cobertura hemos trabajado.

Tabla 1. Elaboración propia

\begin{tabular}{|l|l|c|c|l|}
\hline \multicolumn{1}{|c|}{ Nombre } & \multicolumn{1}{|c|}{ Medio } & \multicolumn{1}{c|}{ Fecha } & \multicolumn{1}{c|}{ Lugar } & \multicolumn{1}{c|}{$\begin{array}{c}\text { Fuerzas } \\
\text { responsables }\end{array}$} \\
\hline Luis Espinal & Aquí & $22 / 03 / 1980$ & La Paz, Bolivia & $\begin{array}{l}\text { Paramilitares } \\
\text { terroristas }\end{array}$ \\
\hline Juantxu Rodríguez & El País & $21 / 12 / 1989$ & Panamá & Estadounidenses \\
\hline
\end{tabular}

${ }^{1}$ Cfr. http://www.rtve.es/alacarta/videos/te-acuerdas/acuerdas-se-cumplen-20-anos-del-asesinato-del-fotografo-juantxu-rodriguez/655611/ [fecha de consulta: 5 de abril de 2013]

2 Hay estudios sobre el papel de los corresponsales de guerra en otros períodos, pero no sobre su fallecimiento. Algunos de esos trabajos se recogen en las referencias bibliográficas finales.

3 Solamente se han llevado a cabo análisis del "caso Couso" relacionados con el Derecho algunos de cuyos títulos consultados figuran en las referencias. 


\begin{tabular}{|l|l|l|c|l|}
\hline Jordi Pujol Puente & Avui & $17 / 05 / 1992$ & $\begin{array}{c}\text { Sarajevo, Bosnia- } \\
\text { Herzegovina }\end{array}$ & $\begin{array}{l}\text { Fuego de mortero } \\
\text { entre serbios y } \\
\text { musulmanes }\end{array}$ \\
\hline Luis Valtueña & Agencia Cover & $18 / 01 / 1997$ & Ruanda & Extremistas hutus \\
\hline Miguel Gil Moreno & Associated Press & $24 / 05 / 2000$ & Sierra Leona & Soldados rebeldes \\
\hline Julio Fuentes & El Mundo & $19 / 11 / 2001$ & $\begin{array}{c}\text { Jalalabad, } \\
\text { Afganistán }\end{array}$ & Talibanes \\
\hline Julio A. Parrado & El Mundo & $7 / 04 / 2003$ & Bagdad, Iraq & Misil iraquí \\
\hline José Couso & Telecinco & $8 / 04 / 2003$ & Bagdad, Iraq & Estadounidenses \\
\hline Ricardo Ortega & Antena 3 & $7 / 03 / 2004$ & $\begin{array}{c}\text { Puerto Príncipe, } \\
\text { Haití }\end{array}$ & $\begin{array}{l}\text { Tiroteo radicales } \\
\text { haitianos }\end{array}$ \\
\hline
\end{tabular}

Exponemos ahora los datos obtenidos desde el punto de vista cuantitativo del vaciado de prensa ordenados de mayor a menor:

Tabla 2. Resultados cuantitativos. Elaboración propia.

\begin{tabular}{|l|c|}
\hline \multicolumn{1}{|c|}{ Periodista } & $\begin{array}{c}\text { Número de } \\
\text { noticias }\end{array}$ \\
\hline José Couso & 59 \\
\hline Julio Fuentes & 40 \\
\hline Ricardo Ortega & 26 \\
\hline Luis Valtueña & 23 \\
\hline Julio A. Parrado & 22 \\
\hline Miguel Gil Moreno & 10 \\
\hline Jordi Pujol Puente & 9 \\
\hline Juantxu Rodríguez & 9 \\
\hline Luis Espinal & 6 \\
\hline
\end{tabular}

La siguiente tabla expone los resultados obtenidos por piezas informativas: Primeras páginas, editoriales, noticias y artículos de opinión.

Tabla 3. Elaboración propia

\begin{tabular}{|c|c|c|c|c|c|c|c|c|c|c|c|c|}
\hline \multirow[b]{2}{*}{ PERIODISTA } & \multicolumn{4}{|c|}{ LA VANGUARDIA } & \multicolumn{4}{|c|}{$A B C$} & \multicolumn{4}{|c|}{ EL PAIS } \\
\hline & $1^{\mathrm{a}}$ pág. & Edit. & Notic & Opin. & $1^{\text {a }}$ pág. & Edit. & Opi. & Not. & $1^{\mathrm{a}}$ pág. & Edit. & Notic & Opin. \\
\hline Luis Espinal & - & - & 3 & - & - & - & - & 2 & - & - & 1 & - \\
\hline & \multicolumn{12}{|c|}{ PIEZAS TOTALES $=$} \\
\hline PERIODISTA & $1^{\mathrm{a}}$ pág. & Edit. & Notic & Opin. & $1^{\text {a }}$ pág. & Edit. & Opi. & Not. & $1^{\mathrm{a}}$ pág. & Edit. & Notic & Opin. \\
\hline Juantxu Rodríguez & - & 1 & 1 & - & - & - & 1 & 2 & 1 & 1 & 2 & - \\
\hline & \multicolumn{12}{|c|}{ PIEZAS TOTALES $=9$} \\
\hline PERIODISTA & $1^{\text {a }}$ pág. & Edit. & Notic & Opin. & $1^{\text {a }}$ pág. & Edit. & Opi. & Not. & $1^{\text {a }}$ pág. & Edit. & Notic & Opin. \\
\hline Jordi Pujol & 1 & - & 4 & 1 & - & - & - & 1 & - & - & 2 & - \\
\hline & \multicolumn{12}{|c|}{ PIEZAS TOTALES $=$} \\
\hline PERIODISTA & $1^{\text {a }}$ pág. & Edit. & Notic & Opin. & $1^{\text {a }}$ pág. & Edit. & Opi. & Not. & $1^{\mathrm{a}}$ pág. & Edit. & Notic & Opin. \\
\hline Luis Valtueña & 1 & 1 & 7 & 1 & - & - & - & 4 & 1 & 1 & 7 & - \\
\hline & \multicolumn{12}{|c|}{ PIEZAS TOTALES $=23$} \\
\hline PERIODISTA & $1^{\mathrm{a}}$ pág. & Edit. & Notic & Opin. & $1^{\mathrm{a}}$ pág. & Edit. & Opi. & Not. & $1^{\mathrm{a}}$ pág. & Edit. & Notic & Opin. \\
\hline Miguel Gil Moreno & - & - & 3 & 1 & - & - & - & 2 & 1 & - & 3 & - \\
\hline & \multicolumn{12}{|c|}{ PIEZAS TOTALES $=10$} \\
\hline PERIODISTA & $1^{\mathrm{a}}$ pág. & Edit. & Notic & Opin. & $1^{\text {a }}$ pág. & Edit. & Opi. & Not. & $1^{\mathrm{a}}$ pág. & Edit. & Notic & Opin. \\
\hline Julio Fuentes & 2 & 1 & 12 & 2 & 1 & 1 & 1 & 7 & 2 & 1 & 8 & 2 \\
\hline
\end{tabular}




\begin{tabular}{|c|c|c|c|c|c|c|c|c|c|c|c|c|}
\hline PERIODISTA & $1^{\mathrm{a}}$ pág. & Edit. & Notic & Opin. & $1^{\mathrm{a}}$ pág. & Edit. & Opi. & Not. & $1^{\text {a }}$ pág. & Edit. & Notic & Opin. \\
\hline Julio A. Parrado & 1 & - & 3 & 1 & 1 & - & 2 & 6 & 1 & 1 & 5 & 1 \\
\hline & & & & & & & & & & & \multicolumn{2}{|c|}{ IEZAS TOTALES $=22$} \\
\hline PERIODISTA & $1^{\text {a }}$ pág. & Edit. & Notic & Opin. & $1^{\mathrm{a}}$ pág. & Edit. & Opi. & Not. & $1^{\text {aa pág. }}$ & Edit. & Notic & Opin. \\
\hline José Couso & 1 & 1 & 8 & 2 & 1 & - & 5 & 19 & 2 & 2 & 13 & 5 \\
\hline & & & & & & & & & & & \multicolumn{2}{|c|}{ IEZAS TOTALES $=59$} \\
\hline PERIODISTA & $1^{\text {a }}$ pág. & Edit. & Notic & Opin. & $1^{\mathrm{a}}$ pág. & Edit. & Opi. & Not. & $1^{\text {a }}$ pág. & Edit. & Notic & Opin. \\
\hline Ricardo Ortega & 1 & 1 & 2 & - & 1 & - & 2 & 6 & 2 & 1 & 8 & 2 \\
\hline & & & & & & & & & & & \multicolumn{2}{|c|}{ PIEZAS TOTALES $=26$} \\
\hline
\end{tabular}

\section{Luis Espinal}

El 22 de marzo de 1980, el sacerdote jesuita y periodista español, director de un semanario de tendencia de izquierdas, fue asesinado por una ráfaga de ametralladoras tras ser torturado por paramilitares en un suburbio de La Paz, Bolivia.

La noticia no fue motivo de portada en ninguno de los rotativos de análisis. Se trata de noticias breves y procedentes de agencia. La Vanguardia le considera una "víctima de la violencia política"4 que ha sido asesinado por grupos terroristas de extrema derecha. Es el diario que ofrece una información más amplia. $A B C$ por su parte, obvia la tendencia política de los terroristas y publica tres breves de agencia. El País incide en la tendencia progresista del sacerdote sin aportar información sobre los terroristas que han asesinado al jesuita.

\section{Juantxu Rodríguez}

El siguiente periodista que ocupa nuestro análisis es un fotógrafo de El País que falleció tiroteado en las calles de Panamá a manos de militares estadounidenses, durante la invasión perpetrada por EE.UU. en diciembre de 1989. Su muerte fue lamentable desde una doble posición, por la pérdida en sí, y porque los mandos estadounidenses dispararon sin control sobre una zona que estaba ocupada por prensa debidamente identificada. Abundando más en los hechos, lo que se llamó "Operación Causa Justa", está considerada una de las operaciones más nefastas, injustas y desproporcionadas desde el punto de vista internacional llevada a cabo por los Estados Unidos $^{5}$. Su similitud con las circunstancias en las que murió el camarógrafo José Couso es palmaria.

Los tres diarios trataron con gran sensibilidad la información sobre el fotógrafo, si bien, la caída de Ceaucescu restó protagonismo a los hechos, sobre todo en La Vanguardia y $A B C$, obteniendo una portada únicamente en el diario al que pertenecía el periodista, con la fotografía a cuatro columnas de Rodríguez abatido en el suelo. $L a$ Vanguardia fue el diario más acrítico con los acontecimientos. El País se comportó de una manera muy lúcida a pesar de la vinculación del fotógrafo con la cabecera, y a pesar de lo controvertido e injusto del asesinato, dado que todas las fuentes coinciden en señalar que fue abatido a tiros en una zona donde no había fuerzas militares dis-

4 "El jesuita catalán Luis Espinal, asesinado", en La Vanguardia, 23 de marzo de 1980, p. 6.

5 Puede encontrarse un análisis sobre la cobertura de aquel conflicto en: MORERA HERNÁNDEZ, Coral (2009: 357-375). 
parando. El rotativo madrileño exige una investigación ${ }^{6}$, pero nuestro análisis confirma que no persigue criminalizar a las tropas estadounidenses, y que consigue una distancia amplia en la cobertura. Si bien, la periodista que acompañaba a Rodríguez en el momento de su fallecimiento, Maruja Torres, sí destaca que el fotógrafo ha sido "una de las víctimas de la actuación indiscriminada de los invasores" $A B C$ no publicó editoriales, pero sí un artículo de opinión sobre los hechos de un tinte más crítico con los mismos (Castro, 1989: 28)8.

\section{Jordi Pujol Puente}

El 17 de mayo de 1992, el fotógrafo catalán Jordi Pujol Puente, que cubría el conflicto bélico en la antigua Yugoslavia para el rotativo Avui, murió en Sarajevo al estallar una granada al paso del vehículo que ocupaba.

Los datos cuantitativos muestran el poco interés informativo que supuso la muerte de este periodista, salvo para el diario catalán La Vanguardia, que consideró que la trágica muerte del periodista era un drama. Aprovechó el fallecimiento de Pujol para criticar con vehemencia una guerra absurda y vergonzosa desde el único artículo de opinión publicado al efecto (PI DI CABANYES, 1992: 25). ABC simplemente informó del hecho en una noticia interior' 9 y El País profundizó en la situación de los reporteros desplazados a situaciones en conflicto y le dedicó un espacio en su última ${ }^{10}$. Abordó la imprudencia e inexperiencia de los periodistas que fueron víctimas de la granada mortal, y en la fatalidad que había acompañado al joven de veinticinco años.

\section{Luis Valtueña}

El 18 de enero de 1997, este fotógrafo de la Agencia Cover, era asesinado en Ruanda junto a dos cooperantes españoles por un grupo de guerrilleros "interhamwe", extremistas hutus, cuando trabajaba como voluntario para la ONG Médicos del Mundo. La noticia alcanza la cobertura más amplia de la observada hasta el momento.

La Vanguardia es el diario que dedicó una cobertura más amplia, para ello publicó una portada a página completa sobre los hechos, si bien, incidiendo en el aspecto de su condición de cooperantes, dos de ellos catalanes, y no en el perfil periodístico del protagonista de nuestro análisis. Por tanto, aunque la cobertura es muy amplia, ésta no está centrada en la labor de Valtueña como periodista sino en el asesinato de tres cooperantes ${ }^{11}$.

6 "Una investigación imprescindible", en El País, 22 de diciembre de 1989, sección Opinión: editorial, p. 6.

7 “Tropas americanas barren a tiros las calles de Panamá para completar su ocupación”, en El País, 22 de diciembre de 1989, portada.

8 En el mismo sentido: "La última foto de su vida", en $A B C, 22$ de diciembre de 1989, p. 35.

9 "Muere un fotógrafo catalán al estallarle una granada en la capital bosniaca", en $A B C, 18$ de mayo de 1992, p. 36.

10 "El corredor de la muerte". Subt. "El fotógrafo Pujol Puente deja la vida en la guerra de Sarajevo", en El País, 18 de mayo de 1992, sección Última, p. 64.

11 “Morir en África", en La Vanguardia, 20 de enero de 1997, sección Opinión, editorial, p. 16. 
$A B C$ mantuvo la misma línea que la cabecera catalana, haciendo énfasis en la cantidad de cooperantes que estaban muriendo en África. No hizo referencia a que fuera fotógrafo, sino responsable de logística y administración en la organización humanitaria. Dedicó, no obstante, una página entera a abordar los hechos, sin llevarlo ni a portadas ni a editoriales.

El País incidió en el perfil humano del fallecido, e hizo más hincapié en su labor como fotógrafo, además de ser cooperante. Dedicó una cobertura extensa: una portada a cuatro columnas, y tres páginas completas. Abordó de forma amplia qué hacía Médicos del Mundo en Ruanda y desde cuándo. Profundizó, por tanto, en la figura de Valtueña como colega, más que en los otros dos cooperantes asesinados; para ello se sirve de las experiencias y relaciones de periodistas de El País con él. Valtueña, para el rotativo madrileño, fue un fotógrafo de profesión con vocación de cooperante. El editorial abordó cómo murieron: de un tiro en la cabeza, y ahondó en la encomiable labor de los cooperantes, sin que los Estados fueran capaces de establecer mecanismos de control para evitar la cifra de voluntarios asesinados en tres meses ${ }^{12}$.

\section{Miguel Gil Moreno}

El 24 de mayo de 2000, un cámara de televisión que trabajaba para la Agencia estadounidense, Associated Press (AP), moría en Sierra Leona al ser alcanzado por los disparos de los soldados rebeldes. Considerado uno de los mejores reporteros gráficos de AP, había salvado la vida en Kosovo y Chechenia, y acababa de recibir el premio al mejor camarógrafo por la Royal Television Society.

Tan excelso curriculum no impresionó a las cabeceras de nuestro análisis que no le dedicaron portadas ni editoriales, excepto por la primera página en El País en una ventana. La Vanguardia incluyó dos fotografías de Gil Moreno y analizó su calidad como camarógrafo y los premios que había obtenido. $A B C$, por su parte, incluyó media página de internacional con su fotografía, haciendo referencia al galardón obtenido, Rory Peck, en $1998^{13}$. El País profundizó más en el fallecimiento de un reportero por vocación, y le dedicó una página completa, y otra con una fotografía del protagonista en un campo de refugiados de $\mathrm{Congo}^{14}$. La información ahondó en la labor de los reporteros de guerra. No quiso relatar cómo murió, sino cómo era, es decir, no en informar de su muerte, sino de la vida de los corresponsales de guerra en general, y de la del que acababa de fallecer en particular.

\section{Julio Fuentes}

El 19 de noviembre de 2001, el enviado especial a Afganistán del diario El Mundo, moría tras el ataque sufrido en una caravana de periodistas cuando se dirigían a la capital afgana desde Jalalabad. Junto a él fueron tiroteados otros tres periodistas -dos de la agencia de noticias Reuters y la corresponsal de El Corriere della Sera-además del

12 "Muertes en Ruanda", en El País, 20 de enero de 1997, sección Opinión, editorial, p. 12.

${ }^{13}$ Cfr. "Asesinado en Sierra Leona el periodista español Miguel Gil Moreno", en $A B C, 25$ de mayo de 1997 , p. 34.

${ }^{14}$ Cfr.: en El País, 26 de mayo de 2000, sección Internacional, p. 6. 
traductor que viajaba con ellos. Julio Fuentes es el segundo reportero fallecido que más atención recibe.

La Vanguardia es el diario que más prudencia muestra en los primeros momentos cuando no estaba confirmado el asesinato de Fuentes. Es la primera vez que hacen un recopilatorio de los periodistas españoles muertos. Afganistán, como conflicto bélico, marca un hito para la cabecera catalana por varios aspectos. En primer lugar por la dificultad de informar desde allí; también por la cantidad de periodistas fallecidos en sólo siete días; y por último, por la tremenda indefensión en que se hayan éstos. Señaló, de hecho, el aluvión de crónicas y reportajes que se habían realizado como consecuencia de la muerte de Fuentes. Incluyeron citas textuales de quien fuera uno de los fundadores de $E l$ Mundo sobre su visión del periodismo de guerra: "Todos éramos piezas reemplazables en el gran mecano de los mass-media" "15. El editorial hizo hincapié en el valor de los reporteros de guerra, para quienes en los conflictos su vida no tenía ni más ni menos valor que la del resto de civiles, de hecho "no son bien recibidos donde hay conflictos"16.

$A B C$ fue más impulsivo que la cabecera catalana en cuanto a dar por fallecido a Julio Fuentes antes de que se confirmara. Dedicó un espacio muy extenso, seis páginas completas. Recuperaron la figura de Miguel Gil Moreno e hicieron también un balance de los reporteros españoles muertos por culpa de los distintos conflictos. Mingote le dedicó una viñeta simulando a San Pedro esperándole en el cielo y preguntándose si sería capaz de quedarse allí sin poder contarle a su periódico lo que estaba ocurriendo ${ }^{17}$. Uno de los artículos de opinión incidió en el asesinato de Fuentes, no en un fatal accidente, y en que dicho asesinato se había producido después de enviar un reportaje muy interesante sobre ampollas letales (Alonso de los Ríos, 2001) ${ }^{18}$.

El País fue más prudente que $A B C$ al hablar de "desaparecidos", si bien en la información interior sí indican que los testigos señalan que han sido asesinados. La cobertura fue muy amplia: una primera página a cuatro columnas y otra con una fotografía y ventana más pequeña. Incluyó abundantes fotografías interiores de los fallecidos, con mayor protagonismo para Julio Fuentes, así como seis páginas completas. Argumentalmente narraron las anécdotas que distintos periodistas de El País tuvieron con Julio Fuentes y explicaron de forma muy gráfica, la tortura sufrida por los periodistas asesinados: fueron lapidados, disparados a bocajarro, en pecho y brazos. $A B C$ llevó esta información a un titular ${ }^{19}$. Si bien, lo que más nos llama la atención del análisis, es el núcleo argumental del diario: la puesta en duda de la autoría de la matanza. En distintas piezas inciden en que han podido ser bandidos y no un grupo de ta-

15 Testimonios de Julio Fuentes citados por García-Planas, 2001: 7).

16 "Matar al mensajero", en La Vanguardia, 20 de noviembre, de 2001, sección Opinión, editorial, p. 26.

${ }^{17}$ Cfr. en $A B C, 21$ de noviembre de 2001, p. 13.

${ }^{18}$ También: "De alto riesgo", en $A B C, 20$ de noviembre de 2001, sección Opinión, editorial, p. 11.

19 "Los ejecutaron a las once de la mañana, con un tiro en la nuca y otro en el estómago", en $A B C, 21$ de noviembre de 2001, sección Internacional, p. 18. 
libanes. Detectamos cierta ambigüedad argumental en torno a los responsables de los asesinatos, aspecto éste no cuestionado en los otros diarios. Para El País, no se sabe quién ha sido y no está demostrado que fueran talibanes "no hay que olvidar que todos los testimonios que se tienen sobre los hechos son indirectos, ya que nadie vio, aunque sí pudo escuchar, lo que ocurrió en el recodo del camino (...)" "º. La argumentación que sostienen al respecto es similar en todas las informaciones: en un país donde todo el mundo lleva armas y sólo las unidades de élite llevan uniformes, es difícil distinguir quién es un asaltador y quién un talibán ${ }^{21}$.

\section{Julio A. Parrado}

E1 7 de abril de 2003, Julio A. Parrado, uno de los cuatro corresponsales del diario $E l$ Mundo en la guerra de Iraq, moría al estallido de un misil tierra-aire en medio del centro de operaciones tácticas de la $2^{\mathrm{a}}$ Brigada de la Tercera División de Infantería de EE.UU. En el mismo ataque habían fallecido un fotógrafo alemán y dos soldados estadounidenses. Consideramos que el parentesco del fallecido, hijo del político Julio Anguita, influyó en la cobertura del periodista. También influyó que un día después muriera José Couso como tendremos ocasión de comprobar.

La información del diario catalán es comedida desde el punto de vista cuantitativo, pero muy expresiva en el plano argumental. Aprovechan la muerte de Parrado para establecer la posición del diario con respecto a la guerra y para hacer propaganda contra ésta. Así lo hace el director del diario quien expresa lo arriesgado de la posición de los corresponsales y la intoxicación que sufren por parte de las administraciones de Saddam y de Bush (Antich, 2003). Le presentan como un "experto en descifrar las mentiras de la Administración Bush" (Robinson, 2003). Y por último hacen un recuento de los muertos en esta guerra y establecen una comparativa en la que advierten que están muriendo "más reporteros que combatientes en términos comparativos"

La portada que dedica $A B C$ es muy similar desde el punto de vista gráfico a la de La Vanguardia: la fotografía principal es para militares estadounidenses, con una pequeña ventana en la parte inferior de la página con la fotografía de Parrado. Dedica, no obstante, bastante información interior: cuatro páginas completas. Consideran a Julio como una persona muy valiente que había abandonado la comodidad de su corresponsalía de Nueva York para irse a la guerra. Nos cuentan cómo era, cuál había sido su trayectoria e incluyen una viñeta de Martín Morales ${ }^{23}$.

El editorial dedicado a los hechos aborda la figura del corresponsal de guerra en el siglo XXI, quien además de desarrollar su trabajo tiene que tener cuidado de que

20 "El cadáver de Fuentes deja Afganistán sin que haya pistas del crimen", en El País, 22 de noviembre de 2001, sección Internacional, p. 4.

21 "Julio Fuentes murió en un ataque de Al Qaeda, según un comandante talibán", en El País, 21 de noviembre de 2001, sección Internacional, p. 4.

22 “Los primeros en caer", en La Vanguardia, 8 de abril de 2003, sección Internacional, p. 8.

${ }^{23}$ Cfr. en $A B C, 8$ de abril de 2003, sección Opinión, p. 10. Un sentido reportaje le dedica su compañera, Mercedes Gallego: "Un negro presentimiento", 9 de abril de 2003, sección Internacional, pp. 14-15. 
no le maten. Nos parece la pieza más rotunda de toda la cobertura en los tres diarios sobre el objeto de nuestro estudio. Considera que quedan lejos los tiempos en que los cronistas escribían sus notas de un día para otro, ahora la guerra se vive en directo gracias a ellos, que tienen que batirse en muchos frentes: los medios electrónicos, la intoxicación informativa y los combates entre los bandos. Gracias a ellos, la opinión pública ha podido conocer conflictos olvidados de África y Asia ${ }^{24}$.

La cobertura dedicada por El País es también más amplia y de mayor hondura por comparativa con La Vanguardia. Los tres diarios coincidieron en el mismo tipo de portada: la invasión contra Saddam a cuatro columnas y una ventana lateral con la fotografía de Parrado. Es decir, el protagonismo lo tuvo la guerra y no la muerte del corresponsal. Incluyeron dos viñetas, una de Forges y otra de Máximo ${ }^{25}$ además de una página completa. La pieza que aporta más datos para el estudio es el editorial. En él también profundizan en el oficio del reportero: duramente castigado en la guerra de Iraq. El carácter de los combates está dificultando mucho la vida de los militares y de los periodistas que viajan con ellos por la multiplicidad de frentes. Consideran que gracias a estos periodistas "incrustados" en las tropas aliadas, estamos "ante la guerra mejor cubierta de la historia y como se ha visto hasta ahora, también de las más peligrosas" ${ }^{26}$. Si no fuera por estos héroes que arriesgan su vida viajando con las tropas, no se estarían conociendo los horrores y errores de este conflicto.

\section{José Couso}

El 8 de abril de 2003, el cámara de Telecinco, José Couso, fallecía a causa de las heridas provocadas por el ataque de un tanque de EE.UU. al hotel "Palestina" de Bagdad, en el que se alojaban la mayoría de los periodistas internacionales que cubrían la información de la guerra en Iraq. Couso se ha convertido en un símbolo al ser el periodista que más cobertura ha recibido en la historia del periodismo español: diez años después de su asesinato se siguen publicando informaciones.

La Vanguardia es el diario que menos cobertura dedicó a la muerte de Couso. Publicó una portada completa a cuatro columnas con la foto del camarógrafo herido en la camilla y con un titular explícito: "EE.UU. dispara a la prensa en Iraq" ${ }^{7}$. Dedicó asimismo cuatro páginas completas a los hechos, en los que argumentalmente se centraron en explicar cómo había muerto y qué estaba ocurriendo en Iraq. El editorial se centró en profundizar sobre el papel vital de la ONU en este conflicto, para luego finalizar con una reseña sobre las dos víctimas españolas que en menos de cuarenta y ocho horas se veían obligadas a regresar a su país en un ataúd ${ }^{28}$. No observamos gestos vehementes ni actitudes que desprendan acritud.

24 "Corresponsales de guerra", en $A B C, 8$ de abril de 2003, sección Opinión, editorial, p. 7.

${ }^{25}$ Cfr. en El País, 8 de abril de 2003, sección Opinión, pp. 20 y 21.

26 "Un duro tributo", en El País, 8 de abril de 2003, sección Opinión, editorial, p. 20.

${ }^{27}$ La Vanguardia, 9 de abril de 2003, sección Portada.

28 “ONU, un papel vital", en La Vanguardia, 9 de abril de 2003, sección Opinión, editorial, p. 30. 
La portada de $A B C$ es muy similar a la de La Vanguardia, con la misma imagen de Couso herido. El espacio dedicado es más amplio: tres páginas enteras de opinión, y siete páginas completas de información. El discurso es también diferente al de la cabecera catalana. Considera el director del diario, José Antonio Zarzalejos, que estas muertes ocurren porque puede haber testigos en esta guerra que no hubo en la anterior, que fue un "fraude". Saca una lanza para defender a la prensa frente al periodismo virtual: ha vuelto "el periodismo real, el del riesgo, el del contacto". Consideramos que se trata de un análisis desproporcionado con los hechos; un alegato hacia la prensa en general, y hacia los enviados por $A B C$ en particular (Zarzalejos, José Antonio 2003). Se incluyeron dos viñetas: una de Mingote en la que alaba la heroicidad, de los corresponsales ${ }^{29}$, y otra de Martín Morales de homenaje al compañero fallecido que pierde la vida por un tanque que sale de la televisión ${ }^{30}$. Por su parte, el enviado especial del diario, Alberto Sotillo, dio cuenta de lo absurdo e injusto de la muerte de Couso y de la irresponsabilidad estadounidense ${ }^{31}$. Otro articulista, Pérez Maura, establece un paralelismo con la guerra de 1991 en la que no murieron periodistas porque escribían sus crónicas desde hoteles de lujo a cientos de kilómetros. En ésta, hay unos héroes que sólo lo son si mueren, y que están contando la guerra sin intermediarios ni intoxicaciones ${ }^{32}$. Jesús Zarzalejos (2003: 23) enarboló un discurso sobre la legislación relativa a los corresponsales de guerra y consideró que matar deliberadamente a un corresponsal en zona de conflicto podría ser considerado como un crimen de guerra. En un sentido diferente se manifestó en una columna Luis Ignacio Parada, al considerar que la opinión pública debía saber que los periodistas se exponían de forma voluntaria a un peligro, y que así lo recogía la Convención de Ginebra de $1949^{33}$.

El diario estableció unas condiciones muy concretas con las que abordar la información sobre el asesinato de Couso y no podemos considerar que la amplitud de la cobertura fuera en beneficio de la calidad de la misma. Las páginas del diario no nos permiten confirmar el interés que el diario pudiera tener por José Couso dado que no aborda la figura del camarógrafo fallecido ni su perfil humano, sino que entona un discurso de opinión muy concreto que parece más preocupado por sus necesidades editoriales en el momento en cuestión ${ }^{34}$.

El País aborda la cobertura del caso de forma amplia, cuatro páginas completas, entra en aspectos que no han abordado los otros periódicos, y también acomete determinadas estrategias informativas que atienden a la línea de confrontación que mantenía el diario en aquellos momentos con respecto a la guerra de Iraq y el gobierno español. Por una parte, nos encontramos con la explicación sin acritud de los hechos,

${ }^{29}$ Cfr. (2003): en $A B C, 9$ de abril, sección Opinión, (p. 9).

${ }^{30}$ Cfr. (2003): en $A B C, 9$ de abril, sección Opinión, (p. 10).

31 "Muere en Bagdad el cámara de Telecinco, José Couso, tras los disparos de un carro de EE.UU.", en $A B C, 9$ de abril de 2003, p. 12.

32 "Esta guerra mejor contada", en $A B C, 9$ de abril de 2003, p. 12.

33 “¿Quién quiere matar al mensajero?”, en $A B C, 9$ de abril de 2003, sección Sumario, p. 2.

34 "Bush lamenta la muerte de José Couso pero no se disculpa ante Aznar", en $A B C, 10$ de abril de 2003, sección Nacional, p. 28. "Los restos mortales de Julio A. Parrado y José Couso salen de territorio iraquí", en $A B C, 12$ de abril de 2003, sección Nacional, p. 21. 
de su situación personal, de cómo era: un buen y experimentado reportero; cómo ocurrió y la complicación de la operación que sobrevendría en muerte. Explican que EE.UU. llevaba tiempo presionando para que los periodistas salieran de Bagdad, y hacía cuarenta y ocho horas que el hotel había pasado a ser considerado un objetivo militar: la estrategia estadounidense pasaba por cortar la ciudad en dos. También explicaron por qué el gobierno español no podía exigir responsabilidades a los EE.UU. por esta muerte, ya que no había antecedentes y se trataba de una baja en un conflicto ${ }^{35}$.

Con respecto al apartado de opinión, dedicó dos editoriales. En el primero de ellos, considera que las últimas horas de la guerra se han convertido en una "tragedia" para los periodistas españoles. Pasa de puntillas por el tema de Couso exigiendo una investigación, para después analizar las dificultades de la posguerra para EE.UU., que ha actuado "como un hiperpoder imperial sin otra guía que la de sus propios intereses" ${ }^{36}$. El otro editorial sí versa, en título y contenido sobre los hechos de forma más clara. Considera que esta guerra ya ha duplicado la muerte de periodistas con respecto a la primera guerra del Golfo pérsico pero no explica por qué. El análisis de los hechos adolece de cierto empaque crítico; considera que Estados Unidos ha actuado mal, que el gobierno español debe dar explicaciones, las responsabilidades penales que pueden exigirse según la Convención de Ginebra, y todo lo que rodea a los hechos ocurridos en el Hotel Palestina, en torno a la "ocultación" y la "mentira" ${ }^{37}$. Forges incluye una viñeta sobre Couso en las páginas de opinión ${ }^{38}$. Los artículos firmados y el espacio dedicado a los hechos es amplio, sin embargo, al igual que consideramos que ocurre con $A B C$, la cantidad no redunda sobre la calidad. Hallamos algunas piezas que no aportan análisis de hondura y son más bien opiniones interesadas y poco críticas. El articulista aborda las muertes de Parrado y Couso en términos cuantitativos, y no distingue que obedecen a circunstancias diferentes (Prado, 2003). Hay otra columna con un nivel de valoración desproporcionado, que aunque se sirve de la noticia de Couso, no aborda el tema en ella. Es una crítica contra el PP, que rescata a "un siniestro Fraga", y que habla del entonces presidente del Gobierno, como "un portero de un sex shop" y de su "obscenidad verbal" con un título muy elocuente: "El Anticristo" (E1 País, 11 de abril de 2003)" 39 . Tampoco resulta relevante el reportaje "El día que llegaron los americanos", que no acomete un análisis de entidad sobre los hechos (Francisco Peregil, 2003). Sin embargo, la información "La guerra detrás de las cámaras" sí analiza en qué situación estaban informando los periodistas, qué diferencias se observan con respecto a Kuwait, y en definitiva, explica desde el punto de vista de una periodista experimentada, qué provocaba que se sintiera más miedo en este conflicto, que en Kosovo, Afganistán o Ruanda. Asimismo, la periodista reconoce que no había sentido

35 "El Ejecutivo buscará alguna vía para ayudar a la familia del cámara muerto en Bagdad", en El País, 11 de abril de 2003, sección España, p. 24.

36 "Planeando la posguerra", en El País, 9 de abril de 2003, sección Opinión, editorial, p. 18.

37 "Hotel Palestina", en El País, 10 de abril de 2003, sección Opinión, editorial, p. 18.

${ }^{38}$ Cfr. en El País, 9 de abril de 2003, p. 18.

${ }^{39}$ En la misma línea se postula Javier Pradera: “Conmoción y espanto”, en El País, 13 de abril de 2003, p. 22. 
censura por parte de los estadounidenses y también explica cómo reciben los iraquíes a los periodistas: "a pedradas" (Rosario Gómez, 2003) ${ }^{40}$.

Encontramos también un análisis que merece nuestra atención por el enfoque. El articulista considera que las sospechas de los controvertidos ataques a tres edificios que albergaban a periodistas en Bagdad no son baladíes y merecen "una indagación". Pero también le merece una consideración especial las circunstancias en las que están trabajando los nuevos periodistas de guerra, que ya no lo son por "vocación" sino por "necesidad". De su precaria situación deberían pedir cuentas a sus empresas según lo entiende el autor (Tertsch, 2003). En la misma línea encontramos una información que atiende la precariedad laboral denunciada por la Federación de Sindicatos de Periodistas (FeSP) en un comunicado llamado "Parrado y Couso, una precariedad sangrante". Aunque Parrado no pertenecía a la plantilla de $E l$ Mundo, se le permitió viajar como corresponsal de guerra; Couso sin embargo, fue enviado como un autónomo: la cámara era de él y no pertenecía a la plantilla de Telecinco ${ }^{41}$.

\section{Ricardo Ortega}

E1 7 de marzo de 2004, el periodista de Antena 3, Ricardo Ortega, fallecía tras recibir dos disparos de bala durante un tiroteo en Puerto Príncipe (Haití). Ortega llevaba poco más de una semana cubriendo el conflicto político en el país y le quedaban escasas horas para abandonarlo.

La cobertura dedicada por La Vanguardia es correcta y sensiblemente inferior al resto de cabeceras. Incluyeron la fotografía de Ortega en el suelo cuando es herido en su portada, y en el interior publicaron otra del periodista en la camilla del hospital aún con vida, además de una página completa sobre el tema. Los únicos datos conclusivos sobre la cobertura tienen que ver con el editorial que abordó la figura periodística de Ortega y el paralelismo con la muerte de Julio A. Parrado, quien como el reportero de Antena 3, había sido una víctima del infortunio. No así la de Couso, insistió el texto, "víctima de un oscuro episodio"42.

$A B C$ dedicó una portada a cuatro columnas con la fotografía de Ortega herido en el suelo, y cuatro páginas completas en su interior, también con la foto del reportero en la camilla aún con vida. No incluyó ningún editorial y sí información relacionada con las circunstancias en las que se produjeron los hechos. El periódico insistió en narrar que Antena 3 había rescindido el contrato de quien fuera corresponsal en Nueva York durante muchos años. Y en la misma línea se mantienen los otros textos que señalaron que Ortega había viajado "tras la excedencia con la que la emisora disfrazara la rescisión de su contrato" ${ }^{43}$.

40 Otra información: José Luis Ferris: "Reporteros”, en El País, 10 de abril de 2003, sección Internacional, p. 2.

41 "Llega a Madrid el cuerpo de Couso en un avión del Ejército", en El País, 13 de abril de 2003, sección España, p. 31.

42 "Morir informando", en La Vanguardia, 9 de marzo de 2004, sección Opinión, editorial, p. 26.

43 "La última guerra de Ricardo Ortega", en $A B C, 9$ de marzo de 2004, sección Internacional, p. 28. 
El País también incluyó la fotografía de Ortega en portada en la camilla antes de fallecer por insuficiencia respiratoria, a tres columnas. Publicó otra fotografía que no incluyeron los otros diarios: se trata del cadáver de Ortega en la camilla del hospital ${ }^{44}$. En la misma línea que vienen abordando la muerte de los periodistas, reseñaron el perfil humano y profesional del fallecido: un periodista curtido a quien no le gustaba la tranquilidad de la redacción. Explicaron la controvertida situación y relación laboral que tenía con la cadena televisiva para quien había viajado a Haití. En el editorial sí expusieron que los periodistas no ignoraban los riesgos de su trabajo y que motu proprio se exponían a él ${ }^{45}$. Aspecto éste que debe tenerse en cuenta con respecto al discurso emitido con motivo del asesinato de otros periodistas. Para el diario, "todo apunta a que los pistoleros dispararon contra los periodistas", por ello consideró que debía pedirse "respeto" y "reconocimiento" para estos héroes que volvían a casa en un ataúd (Valenzuela, 2004).

\section{Resultados}

La diferencia cuantitativa como se desprende de la tabla 2, excepto por el caso de José Couso seguido por el de Julio Fuentes, parece estar sujeta a la evolución del periodismo con el correr de los años: más espacio dedicado a los hechos al disponer de una mayor infraestructura informativa, y mayor énfasis en lo relacionado con noticias negativas: sucesos, catástrofes, etc., como señalan Pratkanis y Aronson (1994) y Wolf (1991).

La única muerte que no fue motivo de portada en ningún diario fue la de Luis Espinal. Aquellas que no fueron susceptibles de publicar un editorial en ninguna de las cabeceras fueron en el caso de los periodistas Luis Espinal, Jordi Pujol Puente y Miguel Gil Moreno. Lo que indica cierta anormalidad informativa en los protocolos de cobertura de la muerte de un periodista cubierto por los propios periodistas.

El único periodista que recibió más de un editorial fue José Couso y a través de $E l$ País. Julio Fuentes es también el único que recibe editoriales en los tres periódicos, hecho que no ocurre con ningún otro reportero fallecido.

Con respecto a los titulares, no observamos alardes expresivos que distraigan la atención del tema, si bien indicamos que el lenguaje más claro con respecto a la cobertura de los hechos se refiere a Luis Espinal: los tres diarios se refirieron al asesinato del sacerdote y director del semanario Aquí; dicho lo anterior también señalamos que es uno de los periodistas fallecidos, que aunque incluido en el listado de los informadores españoles que han perdido la vida en conflictos, ningún titular en ninguna de las tres cabeceras se refirió a él como periodista, sino como "sacerdote" o "jesuita". Tampoco se refirieron a Luis Valtueña, como fotógrafo, periodista o reportero, sino que los titulares reflejaron su condición de "cooperante". En el resto de las informaciones, más contemporáneas a aquellos hechos ocurridos en 1980, observamos cierta tendencia eufemística: "muere por disparos", "muerto a tiros", "deja la vida", "des-

${ }^{44}$ Cfr. en El País, 9 de marzo de 2004, p. 32.

45 “Morir en Haití", en El País, 9 de marzo de 2004, sección Opinión, editorial, p. 12. 
aparecido", "víctima de un ataque". Exponemos sobre qué casos utilizaron también el término "asesinato": La Vanguardia en el caso de Luis Valtueña que lo incluyó en once de los veinte titulares publicados. También lo incluyó $A B C$ para referirse a la muerte de Miguel Gil Moreno, y La Vanguardia para Julio Fuentes. Y por último, en el caso de Ricardo Ortega, tanto en La Vanguardia como en El País. En general los titulares fueron informativos con todos los hechos, excepto en el caso de Couso, que desviaron la atención de la muerte del camarógrafo para atender a otras estrategias, y en el de Juantxu Rodríguez que no quisieron ser claros con lo sucedido. Es especialmente llamativo en El Pais, seguido de $A B C$.

Los dos únicos periodistas que han muerto a manos de tropas estadounidenses son Juantxu Rodríguez y José Couso. El único diario que llevó a su titular a los causantes de la muerte del fotógrafo en Panamá fue La Vanguardia: "El fotógrafo español 'Juanxo' Rodríguez murió por disparos de soldados de EE.UU." ${ }^{46}$. Ni $A B C$ ni El País fueron claros al respecto: "Un fotógrafo español muere en el centro de la capital panameña"47, Antetítulo: "El colaborador de EL PAÍS Juantxu Rodríguez muere por disparos de bala en una zona controlada por EE.UU.", "Tropas americanas barren a tiros las calles de Panamá para completar su ocupación”"48. En el caso de José Couso, los tres diarios expusieron sin tibieza ni eufemismos quiénes fueron los responsables de su asesinato: "Muere un cámara de Tele 5 y otros dos periodistas en ataques de EE.UU."49, "Muere en Bagdad el cámara de Telecinco, José Couso, tras los disparos de un carro de EE.UU." "', "Un tanque de EE.UU. mató a José Couso"s1.

Con respecto a las imágenes difundidas de los periodistas fallecidos, se publicaron fotografías de los periodistas abatidos en el suelo o en camillas, en el caso de Juantxu Rodríguez, José Couso y Ricardo Ortega ${ }^{52}$. En el resto, excepto de Espinal que no hubo imágenes, se incluyó una fotografía bien del rostro o del protagonista con vida en momentos de su actividad. Debemos deducir que la decisión de incluir o no imágenes de la víctima abatida, viene determinada por la posesión o no de las mismas, así como por el nivel informativo, ético y deontológico que su publicación pueda merecer.

El mayor número de páginas impares fue para José Couso, diecisiete, Julio Fuentes, once, y Luis Valtueña, ocho. El único periodista sobre el que hay una discrepancia argumental en el fondo de la cobertura en los tres diarios es Julio Fuentes: El País abogó por una interpretación sobre la autoría de los hechos distante a la mantenida por las otras dos cabeceras. Puede advertirse, no obstante, que el rotativo mantiene una cobertura uniforme sobre la muerte de los periodistas tanto en el plano formal, como en el de contenido. Aboga por un tratamiento desde un fondo más íntimo, y parece ren-

\footnotetext{
${ }^{46}$ en La Vanguardia, 22 de diciembre de 1989, p. 6.

${ }^{47}$ en $A B C, 22$ de diciembre de 1989, p. 35.

48 en El País, 22 de diciembre de 1989, p. 1.

${ }^{49}$ en La Vanguardia, 9 de abril 2003, p. 6.

${ }^{50}$ en $A B C, 9$ de abril de 2003, p. 12.

${ }^{51}$ en El País, 9 de abril de 2003, p. 1.

${ }^{52}$ Sobre el efecto de las fotografías de guerra, son interesantes las reflexiones que plantea Susan Sontag (2010): Ante el dolor de los demás. Barcelona, Random House Mondadori.
} 
dir un homenaje de un mayor calado. En general, se trata de textos que desvelan cómo murieron, si las condiciones fueron especialmente tortuosas, para después ahondar en cómo vivieron su profesión y en cómo eran.

\section{Conclusiones}

La prensa ha presentado la muerte de algunos periodistas como más importante que la de otros, contribuyendo a la formación de actitudes y debates en la esfera pública. La muerte de un periodista español no siempre ha sido objeto de portada, editoriales o artículos de opinión, ni motivo del mismo espacio, sino que ha estado sujeta a la propia agenda informativa. De tal forma que algunos reporteros han visto mermada su atención periodística a causa de hechos que han eclipsado su espacio mediático. Es el caso de Luis Espinal, Juantxu Rodríguez, Jordi Pujol Puente y Miguel Gil Moreno.

Las guerras no son iguales para los medios como tampoco parecen serlo las muertes que de ellas se deriven. Los conflictos que han tenido lugar en Oriente Medio han recibido un tratamiento diferente y superior al de guerras en Latinoamérica, África o la antigua Yugoslavia. El ejemplo más emblemático de lo anterior puede obtenerse si comparamos la cobertura de Juantxu Rodríguez y la de José Couso. A pesar de que la invasión de Panamá fue un caso de tropelía internacional, y a pesar de que la muerte de Rodríguez a manos de mandos estadounidenses identificado como prensa, no ofreció, ni entonces ni ahora, grandes lagunas, en aquel momento no "tocaba", o sencillamente aquel conflicto no merecía ni la atención ni la condena que sí han tenido otras crisis, coincidiendo así con Noelle Newmann en el carácter cíclico del clima de opinión que fomentan los medios de comunicación (1995). Los factores que han influido en la construcción de las noticias están relacionados con el conflicto en sí, y con la atención que éste haya recibido.

Couso, sin embargo, fue el acicate de dos de las cabeceras: $A B C$ y El País. Podemos decir que fue "víctima", no sólo de los tanques de EE.UU. sino de la propia prensa española. Su muerte fue estigmatizada y su figura utilizada para expulsar la ira que despertó aquella guerra; lo que no significa que los medios sintieran más su muerte y ni siquiera que denunciaran la precariedad que estaba afectando al colectivo de los corresponsales de guerra. Julio Fuentes recibió un tratamiento superior comparativamente en cantidad y calidad, lo que confirma ciertas distorsiones subjetivas por parte de las cabeceras. Mientras que la muerte de Couso fue más expuesta al escaparate mediático, la de Fuentes fue abordada para provocar la reflexión.

Miguel Gil Moreno, por su parte, recibió las condolencias por parte de Bill Clinton y Kofi Annan, entre otros. La televisión rusa emitió un programa especial y se proyectó la construcción de un monumento en su honor en Mostar. Estaba reconocido a nivel internacional como lo atestiguan los distintos galardones que obtuvo en vida, pero no sólo no recibió una cobertura muy llamativa, a pesar de la calidad humana del reportero, de su valía profesional y de su trágico asesinato, sino que en su entierro hubo una raquítica representación política, como lamenta un lector de La Vanguardia (Casas Aljama, 2000).

Comparativamente consideramos que las columnas de opinión en $A B C$ y El País ofrecen datos y reflexiones de interés sobre el oficio de corresponsal de guerra que fa- 
cilitan un conocimiento de los hechos de mayor hondura. No hallamos en La Vanguardia tanta profundidad ni variedad de opiniones; el espacio dedicado en general es menor, sin embargo, aborda los hechos con más ponderación y ecuanimidad. Nuestro análisis nos permite confirmar que la cabecera catalana es el rotativo que menos quiere destacar que la muerte de un periodista sea más dramática que la de otros civiles. Para el diario todas las muertes, como todas las guerras, son per se, lamentables. Esto es un dato encomiable desde el punto de vista deontológico por cuanto, si en los conflictos armados la vida de los periodistas no tiene ni más ni menos valor que la del resto de civiles, en las páginas de la prensa no debería computar de un modo diferente. Nuestros datos confirman que sí ocurre atendiendo a criterios relacionados con la agenda informativa, así como con el encuadre que se pueda realizar de los hechos.

La propia evolución periodística, la espectacularización de los contenidos y el mayor impacto perseguido por los medios en aras de lograr más lectores, y por ende, más anunciantes, influye en el hecho de que la muerte de un corresponsal hoy, acaparase, con bastante probabilidad, más interés y cobertura que en otros momentos.

Concluimos nuestro estudio en torno a la siguiente interpretación: no todas las guerras son iguales como tampoco lo son las víctimas que de dichas guerras se produzcan. La vida de un periodista en un conflicto para los periódicos españoles no parece tener la misma relevancia. Si Pérez Maura en $A B C$ consideraba que estos "héroes" sólo lo eran si morían, nosotros vamos un poco más allá al plantear que incluso si mueren, la agenda informativa establecerá si son o no "héroes" a tenor de la atención que reciban.

\section{Referencias bibliográficas}

ALONSO DE LOS RÍOS, César (2001): "La muerte de un testigo", en $A B C, 21$ de noviembre, sección Opinión, p. 15.

ANTICH, José (2003): “Corresponsales de guerra”, en La Vanguardia, 8 de abril, sección Sumario, p. 2.

BULLÓN DE MENDOZA GÓMEZ DE VALUGERA, Alfonso (2009): "Los primeros corresponsales de guerra: España 1833-1840". Cuadernos de investigación histórica, vol. 26, pp. 345-359.

CANO REYES, Jesús (2012): "Palabras entre las bombas: crónicas sobre la guerra civil española de Pablo de la Torriente-Brau, Raúl González Tuñón y Juvencio Valle". Dicenda: Cuadernos de filología hispánica, vol. 30, pp. 161-179.

CASAS ALJAMA, Pedro (2000): "Miguel Gil merecía más", en La Vanguardia, 6 de junio, sección Cartas al Director, p. 31.

CASTRO, Luisa (1989): "Más allá de la foto". $A B C, 30$ de diciembre, sección Opinión, p. 28

FERNÁNDEZ LIESA, Carlos (2011): "El asunto Couso en los tribunales nacionales y en las relaciones internacionales". Revista española de derecho internacional, vol. $63, \mathrm{n}^{\circ} 2$, pp. 145-160. 
FERRIS, José Luis (2003): “Reporteros”, en El País, 10 de abril, sección Internacional, p. 2

GALLEGO, Mercedes (2003): "Un negro presentimiento", en $A B C, 9$ de abril, sección Internacional, pp. 14-15.

GARCÍA-PLANAS, Placid (2001): "Un salto tan suave", en La Vanguardia, 20 de noviembre, sección Internacional, p. 7.

GÓMEZ, Rosario (2003): “La guerra detrás de las cámaras", en El País, 13 de abril, sección Especial Domingo, p. 10.

MARTÍNEZ SALAZAR, Ángel (1998): "Los primeros corresponsales de guerra españoles". Historia 16, n 272 , pp. 88-95.

McCOMBS, Max. y SHAW, Donald L. (1972): "The agenda-setting function of the mass media". Public Opinion Quarterly, vol. 36, pp. 176-185.

MILLÁS, Juan José (2003): "El anticristo", en El País, 11 de abril, sección Última, p. 88.

MORERA HERNÁNDEZ, Coral (2009): "La invasión norteamericana de Panamá (1989): una mirada desde España". Anuario del Centro de Estudios Históricos "Prof. Carlos S. A. Segreti", vol. 9, no 9, pp. 357-375.

MUÑOZ, Luna (2006): "Couso, en la búsqueda de la justicia y la verdad". Cuadernos para el diálogo, $\mathrm{n}^{\circ} 7$ (febrero), pp. 92-95.

NOELLE-NEUMANN, Elisabeth (1995): La espiral de silencio. Opinión pública, nuestra piel social. Barcelona, Paidós.

PEREGIL, Francisco (2003): "El día que llegaron los americanos", en El País, 13 de abril, sección Especial Domingo, p. 9.

PÉREZ CEPEDA, Ana Isabel (2005): "Crímenes de guerra. Especial referencia al caso Couso". Revista penal, $\mathrm{n}^{\circ}$ 15, pp. 105-136.

PI DI CABANYES, Oriol (1992): "Brigadistas", en La Vanguardia, 21 de mayo, p. 25.

PRADERA, Javier (2003): "Conmoción y espanto", en El País, 13 de abril, p. 22

PRADO, Benjamín (2003): "Los cómplices", en El País, 10 de abril, sección Opinión, p. 31.

PRATKANIS, Anthony, y ARONSON, Elliot (1994): La era de la propaganda. Uso y abuso de la persuasión. Barcelona, Paidós.

ROBINSON, Andy (2003): "Descifrando mentiras", en La Vanguardia, 8 de abril, sección Internacional, p. 8.

SONTAG, Susan (2010): Ante el dolor de los demás. Barcelona, Random House Mondadori.

SUÁREZ VILLEGAS, Juan Carlos (2001): Análisis ético de la información. Sevilla, Mad. 
TERTSCH, Hermann (2003): "Periodistas en guerra", en El País, 11 de abril, sección Internacional, p. 10.

TOMÁS ORTIZ DE LA TORRE, José Antonio (2004): "El caso «Couso»: ¿Tienen jurisdicción los Tribunales de España?". La Ley: Revista jurídica española de doctrina, jurisprudencia y bibliografía, $\mathrm{n}^{\circ}$ 4, pp. 1593-1598.

TORRES BOURSAULT, Leopoldo (2009): “El asunto José Couso: la sanción de los crímenes internacionales en los sistemas nacionales y los mecanismos de cooperación”, en CUERDA RIEZU, Antonio Rafael y JIMENEZ GARCÍA, Francisco (coords.): Nuevos desafios del derecho penal internacional: terrorismo, crimenes internacionales y derechos fundamentales. Madrid, Tecnos. pp. 237-260.

VALENZUELA, Javier (2004): "Dejad el balcón abierto", en El País, 9 de marzo, sección España, p. 32.

VV. AA. (2010): Código Deontológico Federación de Asociaciones de Periodistas de España, www.fape.es/codigo-deontologico.htm [fecha de consulta: 1 de marzo de 2013]

VV. AA. (1999): Libro de Estilo. Madrid, Ediciones El País.

WOLF, Mauro (1991): La investigación en comunicación de masas. Crítica y perspectivas. Barcelona, Paidós.

ZARZALEJOS, José Antonio (2003): "Periodismo real", en $A B C, 9$ de abril, sección Opinión, p. 5.

ZARZALEJOS, Jesús (2003): “Guerra y periodismo", en $A B C, 11$ de abril, sección Opinión, p. 23. 